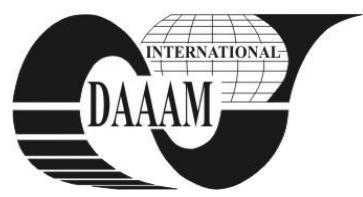

Annals of DAAAM for 2011 \& Proceedings of the 22nd International DAAAM Symposium, Volume 22, No. 1, ISSN 1726-9679 ISBN 978-3-901509-83-4, Editor B. Katalinic, Published by DAAAM International, Vienna, Austria, EU, 2011 Make Harmony between Technology and Nature, and Your Mind will Fly Free as a Bird Annals \& Proceedings of DAAAM International 2011

\title{
INFORMATION QUALITY
}

MALA, J[ana]; HASAYOVA, M[artina] \& BIELIK - MARETTOVA, M[aria]

\begin{abstract}
This article describes examining approaches to quality management information. It is based mainly on the authors: prof. R. Wang, prof. Y. Lee, prof. D. Strong and prof. L. Pipino. In the end I describe the research areas of information quality in project management

Key words: information quality, TDQM, data quality assessment
\end{abstract}

\section{INTRODUCTION}

The information quality management in project management is the area that was until now not specifically defined. This article presents the basic problem areas of information quality like information quality dimensions and the selected methods for the information quality measurement. Those methods are the basis for the future research in the area of information quality in project management.

"Quality management is performed throughout the project lifecycle with special attention to:

- Quality Planning,

- Quality Assurance,

- Quality Control,

- Independent Verification and Validation (2010)."

\section{INFORMATION QUALITY}

When the organizations want to achieve a state of highquality of information, it is necessary for them to implement Total Data Quality Management (TDQM).

Prof. Richard Y. Wang a pioneer and international known leader in the date quality field, adapted Deming's method of defining, measuring, analyzing and improving products to the information manufacturing environment, and proposed TDQM, which emphasizes the importance of continuous improvement and delivery of high-quality information products (Hakim, 2007).

Proposed TDQM methodology is based on research and accumulated experience. Defining, measuring, analyzing and improving the quality of information are essential steps to ensure the quality of the information of product. The definition component of the TDQM cycle identifies important IQ dimensions and the corresponding IQ requirements. The measurement component produces IQ metrics. The analysis component identifies root causes for IQ problems and calculates the impacts of poor quality information. Finally, the improvement component provides techniques for improving IQ. Prof. Wang (Wang, 1998) refers to an information manufacturing system as a system that produces information products. The concept of Information Product (IP) is introduced to emphasize the fact that the information output from an information manufacturing system has value that is transferable to the consumer. According to the TDQM prof. Wang identifies four roles:

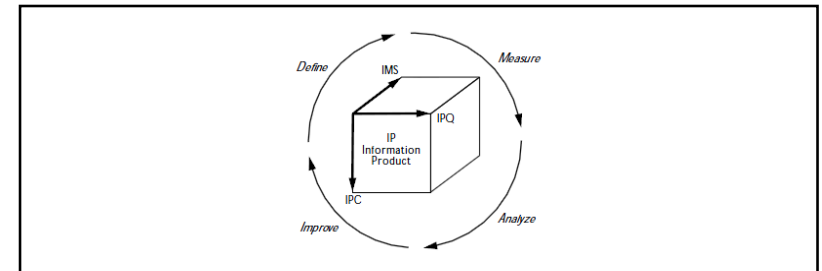

Fig. 1. The scheme of the TDQM methodology (Wang, 1998)

- Information suppliers are those who create or collect data for the IP.

- Information manufacturers are those who design, develop, or maintain the data and systems infrastructure for the IP.

- Information consumers are those who use the IP in their work.

- IP managers are those who are responsible for managing the entire IP production process throughout the IP life cycle (Wang, 1998).

The scheme at the figure 1 presents the TDQM methodology. IMS - Information Manufacturing System, IPC IP Characteristic and IPQ - IP Quality.

When the organizations want to apply this methodology, they have to comply with these steps (Wang, 1998):

(1) Clearly articulate the IP in business terms

(2) Establish an IP team considering of a senior executive as the TDQM champion, an IP engineer who is familiar with the TDQM methodology, and members who are information suppliers, manufactures, consumers, and IP managers

(3) Teach IQ assessment and IQ management skills to all the IP constituencies

(4) Institutionalize continuous IP improvement.

\subsection{Winding road to the Information Quality}

Poor information quality can create chaos in the organization. It is necessary to diagnose the root that causes this situation. Professors Strong, Lee and Wang in (Strong et al., 1997) described 10 key IQ problems. Most of them are relevant also today:

Multiple sources of the same information produce different values. One of the warning signs for this IQ problem is when different systems are developed for different purposes that require the same information.

Information is produced using subjective judgments, leading to bias. Information stored in organizational databases is considered to be factual. The process, by which these "facts" are collected, however, may involve subjective judgments. To avoid subjective judgment more training, better rules and expert systems should be on place.

Systematic errors in information production lead to lost information. Because IQ involves more than just correctness or accuracy, we focus not on errors (mistakes), but systematic 
problems. Some errors in producing information, however, are actually systematic problems. Recommended solutions for this problem are: Statistical process control; process improvement; behavioral control and proper incentives.

Large volumes of stored information make it difficult to access in a reasonable time. Large volumes of information present problems for those responsible for storing and maintaining the information and for those searching for useful information. It is a problem in the accessibility aspect of IQ, but it also affects the timeliness of the information and the valueadded dimensions of information.

Distributed heterogeneous systems lead to inconsistent definitions, formats, and values.

The most common IQ problem associated with distributed systems is inconsistent information-information that has either different values or different representations across systems. Different values are generated from multiple sources or created by inconsistent updating of multiple copies. Different representations (formats or codes) must be accommodated when autonomously designed systems are integrated.

\subsection{Data Quality Assessment}

How good is a company's data quality? Professors Pipino, Lee and Wang described the principles, which can organizations help to create their own metrics. Studies have confirmed that data quality is a multidimensional concept (Pipino et al., 2002). Companies have to deal with two things, namely:

- The subjective perceptions of the individuals involved with the data,

- The objective measurements based on the data set in question.

Subjective quality assessment of data reflects the needs and experiences of all stakeholders. If stakeholders measure the quality of data as poor, their behavior will affect the evaluation of such information. It is therefore possible to prevent such situations and use a questionnaire to measure stakeholder perceptions to assess data quality. Objective assessments can be task-independent or task-dependent. Task-independent metrics can be used to any data set, regardless of the tasks at hand. Task dependent metrics are developed in specific application contexts. Professors Pippin, Lee and Wang (Pippin et al., 2002) in their study indicated an approach that combines subjective and objective evaluation of data quality and it also illustrates how it can be used in practice.

When the organizations want to do an objective assessment, they should follow a set of principles to develop metrics specific to their needs. Three pervasive functional forms are:

- Simple Ratio,

- Min or Max Operation,

- Weighted Average.

Simple Ratio - "The simple ratio measures the ratio of desired outcomes to total outcomes." Many traditional data quality metrics, such as free-of-error, completeness, and consistency take this form. Other dimensions that can be evaluated using this form include concise representation, relevancy, and ease of manipulation. (Pipino, 2002)."

Min or Max Operation - "It is used to handle dimensions that require the aggregation of multiple date quality indicators, the minimum or maximum operation can be applied. One computes the minimum (or maximum) value from among the normalized values of the individual data quality indicators. The minimum operation is conservative in that it assigns to the dimension an aggregate value no higher than the value of its weakest data quality indicator (evaluated and normalized to between 0 and 1). The maximum operation is used if a liberal interpretation is warranted. The individual variables may be measured using a simple ratio.

Weighted Average - "it is used for the multivariable case, an alternative to the min operator is a weighted average of variables. The company wants to insure the rating is normalized, each weighting factor should be between zero and one, and the weighting factors should add to one. Regarding the believability, if the company can specify the degree of importance of each of the variables to the overall believability measure, the weighted average may be an appropriate form to use (Pipino et al., 2002)."

\section{CONCLUSION}

According to the described methods for information quality measurement, we have designed further research in information quality in project management in industrial enterprises in Slovak republic. Information quality in project management is still underestimated and is not clearly linked with the project quality.

The research is oriented on the analysis of following problem areas:

- Relationship between project management maturity and informarmation quality,

- Relationship between information management in project management and the information quality,

- Relationship between project management tirangle (time, scope, cost) and information quality.

Previous researches of the project management in Slovak industrial enterprises managed at the Institute of industrial engineering, management and quality brought some interesting results in the area of project management maturity, training needs in project management, project management methods and methodologies applied in industrial enterprises (Holtan et al., 2009), multicultural project teams (Caganova et al., 2011)and ICT support of project management. Research of information quality in project management is a logical continuation of previeous researches with the objective to improve project quality in industrial enterprises.

\section{REFERENCES}

Hakim, L. (2007). Information Quality Management: Theory and Applications, Idea Group Publishing, ISBN 1-59904024-7

Pipino, L.; Lee, Y.; Wang, R. (2002). Data Quality Assessment. Communications of the ACM, Vol. 45, No. 4ve, (April 2002) pgs. 211-218, ISSN 0065-7014

Strong, D.; Lee, Y.; Wang, R. (1997). 10 Potholes in the Road to Information Quality. In: Computer, Vol. 30, No. 9, (September 1997) pgs. 38-46, ISSN 0018-9162

Wang, R. (1998). A Product Perspective on Total Data Quality Management. In: Communications of the ACM, Vol. 41, No. 2, February 1998. pgs. 58-65, ISSN 0001-0782

Holtan, M., Kremeňová, I., Šujanová, J.: Directing successful projects with PRINCE2. In: CO-MAT-TECH 2009. Proceedings of the 17th International Science Conference, Trnava 22.-23. October 2009. - Trnava : AlumniPress, 2009. - ISBN 978-80-8096-100-8. - pgs. 130-136

Cagáňová, D., Šujanová, J., Čambál, Miloš: The Multiculturality Aspects in Knowledge Management within the Slovak Industrial Enterprises.In: Proceedings of the 12th European Conference on Knowledge Management ECKM 2011 : University of Passau, Germany, 1-2 September 2011. - Passau : University of Passau, 2011. ISBN 978-1-908272-10-2. - pgs. 126-127 